\title{
INVESTIGACIONES
}

\section{Competencias docentes interculturales. Multiculturalidad y consecuencias para la inmigración ${ }^{1}$}

\author{
Intercultural teaching competences. \\ Multiculturalism and consequences for immigration
}

Jorge Alarcón Leiva ${ }^{a}$,José Juan Márquez Sánchez

${ }^{a}$ Universidad de Talca, Chile. joalarcon@utalca.cl

${ }^{b}$ Universidad de Talca, Chile. sanchez_jufi@hotmail.com

\section{RESUMEN}

La implementación de la reforma educativa en el nivel medio superior mexicano ha supuesto cambios en el currículum y en la formación de los docentes. Este trabajo tiene como propósito examinar las características de las competencias docentes de los profesionales de la educación intercultural de los bachilleratos integrales comunitarios del Estado de Oaxaca; esto con el propósito de articular y desglosar un perfil de competencias de tales docentes.

La metodología de investigación se sustentó en la revisión documental referida a las competencias docentes en contextos de interculturalidad. Los resultados obtenidos permitieron identificar las competencias interculturales para la definición de un perfil orientado a la formación de profesores del Bachillerato Integral Comunitario.

Las conclusiones de este estudio revelan la importancia del desarrollo de estas competencias en los docentes, imprescindibles para desempeñar adecuadamente su rol profesional.

Palabras claves: Formación del profesorado, ámbitos de desempeño, indicadores de desempeño.

\section{ABSTRACT}

The implementation of the educational reform in the mexican upper secondary level has brought about changes in the curriculum and in the training of teachers. The purpose of the work is to examine the characteristics of the teaching competencies of the professionals of intercultural education of the integral community baccalaureates of the State of Oaxaca; this with the purpose of articulating and breaking down a profile of competences of such teachers.

The research methodology was based on the documentary review, referring to the teaching competences in intercultural contexts. The results obtained allowed the identification of intercultural competences for the definition of a profile oriented to the formation of teachers of the Integral Community Baccalaureate.

The conclusions of this study reveal the importance of the development of intercultural competences in teachers, essential to adequately perform their professional role.

Key words: Teacher training, performance scopes, indicators of performance.

\footnotetext{
1 Este artículo es producto del Proyecto Anillo de Investigación en Ciencias Sociales y Humanidades Nº1401, denominado "Inmigrantes en el sistema educacional de Chile. Representaciones de género, lengua, territorialidad y exclusión social" financiado por CONICYT, Chile.
} 


\section{PRESENTACIÓN}

Para concluir, somos diversos, pero somos diversos de modos diferentes.

A. K. Sen (1997)

Según la Constitución Política de los Estados Unidos Mexicanos, la educación intercultural es un derecho de todo individuo (Art. $2^{\circ}$ B. II). Por su parte, en el año 1989 la Organización Internacional del Trabajo (OIT) promulgó el Convenio $\mathrm{N}^{\circ} 169$ Sobre Pueblos Indígenas y Tribales en Países Independientes. Tales referencias, entre otros propósitos, persiguen como objetivo resguardar las garantías de una educación integral para las comunidades originarias en los diferentes niveles de enseñanza. A partir de lo anterior, se desarrollan proyectos estratégicos para lograr la cobertura de los servicios educacionales orientados a los grupos étnicos de la república mexicana.

El Estado tiene la obligación de brindar educación, sin distinción alguna; asimismo, debe diseñar e implementar políticas educativas atendiendo a las particularidades de las comunidades indígenas que convergen en el país, ya que México se destaca por ser una nación multicultural (República de los Estados Unidos Mexicanos, Art. $2^{\circ}$ B. II). Por lo mismo, el currículum nacional como documento rector de la formación contempla características y manifestaciones culturales de la diversidad étnica presente en todo el territorio nacional, en el que convergen un total de 85 lenguas y 62 pueblos indígenas. Es por esto que en México se han implementado planes y programas educativos para atender la diversidad multicultural de niños y jóvenes mediante un enfoque intercultural. Los responsables de ofertar y dar cumplimiento a dichos programas son los organismos e instituciones administrativas cuyo propósito es diseñar programas de estudio que integren elementos distintivos de cada región.

En el Estado de Oaxaca la educación intercultural en el nivel medio superior se desarrolla mediante los Bachilleratos Integrales Comunitarios (BIC) ${ }^{2}$, cuyo propósito es retomar y valorar las acciones y estrategias de trabajos interculturales desarrollados en esta modalidad educativa en la educación estatal, tales como el currículum y programas de estudio interculturales, la formación inicial y continua de los docentes, los materiales y medios didácticos, la infraestructura educativa, el equipamiento tecnológico y los programas de fortalecimiento estudiantiles. Lo relevante en este punto son las acciones y estrategias relacionadas con la formación inicial y continua de los profesores ${ }^{3}$.

Para garantizar una educación intercultural acorde a los lineamientos de la Reforma Integral a la Educación Media Superior, así como para dar cumplimiento al currículum y los programas de estudio que desarrollen dichas competencias en los jóvenes, es preciso analizar el papel que desempeñan los profesores al impartir docencia en un contexto multicultural (Gómez, 2010). Desde luego que no es el único factor determinante, pero ciertamente la función docente es esencial para comprender el éxito de los sistemas

El Bachillerato Integral Comunitario (en adelante, BIC) definió para su operación un Modelo Educativo Integral Indígena (MEII), que se orientó desde sus inicios a la selección del método (o métodos), relacionados con la teoría del conocimiento, para definir los criterios propios para el proceso de enseñanza y aprendizaje de acuerdo con los principios filosóficos educativos que mejor representan los anhelos de las comunidades.

3 En lo sucesivo, y siguiendo un estándar ampliamente aceptado, el artículo utilizará indistintamente las expresiones "profesores" y "docentes", considerándolas sinónimas. En cuanto a género y el número, el texto hará distingos únicamente cuando el contexto lo exija. 
escolares. A partir de lo anterior surgen las siguientes interrogantes, ¿los profesores disponen de las competencias interculturales necesarias para impartir clases y así atender la diversidad en el aula de un Bachillerato Integral Comunitario? y ¿cuáles son esas competencias?

Guiado por estas interrogantes, el trabajo tiene como objetivo identificar las competencias que el docente debe presentar durante su formación continua y de esta forma atender la diversidad cultural a la que están orientados sus servicios pedagógicos. A fortiori, el artículo ofrece una caracterización de competencias para la docencia en contextos interculturales más allá del caso de Oaxaca, por lo que se establecerán relaciones entre la situación de dicho estado mexicano y Chile.

Sobre este último punto, es muy relevante la relación entre multiculturalidad, interculturalidad e inmigración extranjera. En pocas palabras, la interculturalidad es la expresión pedagógicamente programática de abordar la multiculturalidad de un determinado colectivo humano. Esta expresión adopta formas más o menos definidas caso por caso, pero en todos ellos la interculturalidad presenta dos rasgos fundamentales que resultan interesantes para lo expuesto con anterioridad. En primer lugar, las características de la multiculturalidad que se da en Oaxaca es el resultado de la convivencia en un mismo espacio físico y simbólico de una enorme diversidad de pueblos y lenguajes que, entre otras cosas, deben relacionarse a partir de sus respectivas identidades. Esto es muy similar a lo que ocurre en Chile, considerando la ola de inmigrantes que se ha hecho presente en el país. En segundo lugar, la interculturalidad se constituye en un enfoque pedagógico sugerente para abordar los requerimientos de la inmigración extranjera y pone en evidencia la necesidad de integrarlo tanto en la formación inicial como en la formación continua de los docentes (Sáez, 2008). Así, el caso institucional de Oaxaca resulta instructivo para Chile.

Tras esta aclaración preliminar, el artículo se organiza a partir de la pregunta señalada en cuatro secciones. A continuación, se ofrecerá una breve síntesis de los hitos históricos de la educación intercultural y su relación con la formación de los docentes en México. En la tercera sección se establece una relación entre interculturalidad y educación comunitaria, para hacer hincapié en la idea de que entre ambas ha de darse una relación intrínseca. En la cuarta sección se ofrece una aproximación más concreta a las competencias interculturales, su relación con el modelo educativo y, en definitiva, con el perfil del docente; esta aproximación constata las relaciones y a su vez perfila la posibilidad de definir un perfil que integre algunos elementos de los que adolece el actual sistema docente. De ahí que, en la quinta sección, se elabore una propuesta con un desglose de ámbitos, competencias o atributos e indicadores de desempeño. Finalmente, en las consideraciones finales se analiza algunas de las consecuencias del análisis para la situación educativa chilena actual, caracterizada -entre otros aspectos- por la presencia creciente de la inmigración extranjera.

Una última consideración se impone y es la siguiente: las reformas que adoptan el modelo por competencias son importantes en cobertura y número en varios lugares del mundo, en todas ellas se reconoce la presencia de elementos heteróclitos y de algunos componentes esenciales (Ettayebi, Opertti y Jonnaert, 2008); entre estos componentes se halla el perfil de egreso y sus características fundamentales (Perrenoud, 1998). Consecuentemente, un conjunto de referencias autorizadas así lo indican y es lo que se ha seguido como orientación en este trabajo (Tardif, 2003). 


\section{MULTICULTURALIDAD, EDUCACIÓN INTERCULTURAL Y FORMACIÓN DOCENTE EN MÉXICO}

México es un país rico en múltiples aspectos: manifestaciones culturales, tradiciones, música, gastronomía, vestimenta, lenguas y saberes ancestrales, entre otros; esto la convierte en una nación con una multiculturalidad distintiva. Según UNESCO (2002), la diversidad cultural constituye una verdadera fuerza para el desarrollo, inclusive respecto al crecimiento económico, pero especialmente es un medio inapreciable para tener una vida intelectual, afectiva, moral y espiritual más rica.

La república mexicana es un territorio donde convergen más de 85 lenguas originarias y 60 comunidades indígenas. Particularmente, en el estado de Oaxaca, conviven 18 grupos étnicos de los 65, con rasgos y características culturales propias que lo convierten en un país multicultural. El multiculturalismo, según Jiménez y Malgesini (1997), es la ideología o modelo de organización social que afirma la posibilidad de convivir armoniosamente en sociedad entre aquellos grupos o etnia, cultural, religiosa o lingüísticamente diferentes. El multiculturalismo valora positivamente la diversidad sociocultural y asume como punto de partida que ningún grupo tiene que perder su cultura o identidad propia; en efecto, la diversidad existente no desaparece sino que se mantiene, se recrea; no desaparece ni por adquisición de la cultura dominante y abandono de la original ni por el surgimiento de una cultura integradora con los aportes de los preexistentes. La diversidad cultural se considera algo bueno y deseable, se fomenta la práctica de tradiciones etnoculturales.

El multiculturalismo presente en México, en general, y en Oaxaca en particular, tiene lugar en un marco de respeto e igualdad a los principios, normas de convivencia y organización de la vida comunitaria, valores y creencias religiosas ancestrales. No obstante, al convivir e integrarse en sus relaciones culturales, estas comunidades fomentan la interculturalidad en un marco de convivencia. Dicho por ahora de forma aproximativa, la interculturalidad puede entenderse como la interacción entre culturas, vale decir, como el proceso de comunicación entre diferentes grupos humanos con costumbres distintas, cuya característica fundamental es "la horizontalidad" de las relaciones entre sus miembros: ningún colectivo o individuo está por encima del otro, de esta manera se promueve la igualdad, la integración y la convivencia armónica entre todos.

La mencionada "horizontalidad" no es solo una figura o una imagen que permite representar las relaciones entre individuos, es, de hecho, un rasgo descriptivo propio del encuentro entre grupos que no hacen de las jerarquías el estándar de su vinculación recíproca. Desde luego, tal horizontalidad no resulta fácil, máxime cuando tiende a pensarse que es inherente a la estructura social la existencia de una cierta verticalidad que, entre cosas, justifica la primacía de ciertas personas o grupos por sobre otros. No es el momento para emprender una crítica a esta preconcepción, aunque es importante indicar que se trata de una preconcepción que, como otras tantas, puede ser revisada.

El enfoque intercultural plantea este principio como eje articulador de la convivencia entre culturas que habitan en un mismo territorio, donde la interacción confluye a partir de las necesidades y mecanismos de movilización en las regiones del país y por diversas razones. Las interacciones están marcadas por el respeto y la igualdad, nadie es más importante que el otro, ya que cada uno tiene un rasgo identitario que lo hace único y del cual el otro aprende. Es precisamente la educación la que juega un papel preponderante a este respecto (Valverde, 2010). 
La educación intercultural, en la historia educativa de la nación mexicana, ha ocupado un lugar significativo en las políticas educativas y periodos históricos. Se inicia con el México postrevolucionario y garantiza educación para los indígenas como muestra de apoyo por la participación en el movimiento revolucionario; sin embargo, la lucha de los indígenas en el movimiento obedeció al rescate de sus tierras y la implementación de un modelo de estado basado en la comunalidad (Gómez, 2010).

El primer hito al que responde la educación impartida en las comunidades indígenas en los años treinta respondió a integrarlos a la forma de vida de la sociedad de la época, bajo el enfoque llamado "indigenismo" (Dietz, 2014). Así, todos los proyectos educacionales coordinados por la naciente Secretaría de Educación Pública (SEP) y dirigidos por José Vasconcelos, tenían el propósito de aculturizar a los pueblos indígenas para lograr su integración a la vida nacional. Es así como surgen los programas de estudio, la capacitación de promotores culturales y maestros bilingües para enseñar la lengua castellana al niño(a) indígena y así alfabetizar a la población; estos son los pasos iniciales de la interculturalidad. No obstante, los promotores culturales y maestros bilingües no cubrieron todas las expectativas del proceso de aculturización; en primer lugar, por no contar con las habilidades y competencias necesarias; en segundo, por la carga excesiva de trabajo al atender otras actividades ajenas a la enseñanza.

De esta forma se evidenciaron las debilidades en la formación de promotores y maestros bilingües, puesto que no contaban con los conocimientos, habilidades y competencias pedagógicas necesarias para implementar las acciones de los programas educativos; sumado a lo anterior, la mayoría no eran originarios de la localidad a la que estaban destinados. Ante esta situación, en 1978 la SEP implementa una reestructuración curricular de los planes de formación inicial y actualización docente para garantizar una educación de calidad.

En el segundo hito de la educación intercultural, entre los años 1980 al 2000, surge el movimiento particular de las comunidades indígenas que pudiera identificarse como la movilización étnica y el multiculturalismo indígena, cuyo propósito fue revindicar los derechos y garantías de los pueblos indígenas, generar mayores oportunidades e igualdades de acceso a los asuntos del Estado y la permisividad de una organización de gobierno particular a sus intereses. A este respecto, se propusieron reformas a partir de la firma del Convenio $N^{\circ} 169$ de la Organización Internacional del Trabajo (OIT) sobre "Los pueblos indígenas y tribales en países independientes" de 1989, en el cual el Estado reconoce la composición pluricultural y multilingüe de las comunidades originarias; aun así, no se les reconoce autonomía a estas comunidades.

Asimismo, las peticiones y sugerencias de los indígenas estuvieron orientadas a contar con una educación acorde a sus intereses y características, que respetara sus principios y normas internas de convivencia. Para ello, la SEP crea el Departamento de Educación Indígena cuya tarea es garantizar una educación bilingüe a los estudiantes indígenas que promueva el diseño de proyectos curriculares y acciones de capacitación a los maestros de las escuelas rurales. Sin embargo, los esfuerzos de este departamento no fueron suficientes ya que la formación y capacitación de los docentes fue superficial, breve e inadecuada para los contextos culturales donde desempeñaron sus funciones.

El tercer hito abarca del 2000 a la fecha, con el reconocimiento formal y legal de las comunidades indígenas por parte del gobierno de la transición, más conocido como el "indio permitido" (Hale, 2007, citado en Dietz, 2014), con el que oficialmente la 
educación intercultural y bilingüe se presenta como una forma de reivindicar los derechos y oportunidades negadas por décadas a las comunidades originarias. Por consiguiente, entre las acciones de la nueva política intercultural se crea la Coordinación General de Educación Intercultural y Bilingüe (CGEIB), organismo encargado de rediseñar el currículum y programas de estudio de los diferentes niveles educativos, integrando materias que consideren elementos de la región donde se localiza la comunidad. Entre otras funciones de esta coordinación destacan la implementación de programas de formación y actualización docente para profesores que imparten clases en escuelas interculturales. ${ }^{4}$

De cierto modo, las acciones y programas de desarrollo profesional docente aún no han impactado efectivamente en la formación y actualización de los docentes, ya que existen ciertas carencias en los programas formativos, lo que implica que se debió revisar el currículum para garantizar que los contenidos enfocados al desarrollo de competencias interculturales proporcionaran herramientas didácticas y pedagógicas para atender la diversidad en el aula; puesto que solo así se podrá hablar de una verdadera educación intercultural. En definitiva, es necesario seguir construyendo las bases para una educación intercultural que no sea solo para las comunidades indígenas, sino para la sociedad mexicana en general, a pesar de existir aun el estigma de que los indígenas no tienen derecho a mejores oportunidades.

\section{INTERCULTURALIDAD Y EDUCACIÓN COMUNITARIA: UN PLEXO INDISCERNIBLE EN EL BIC}

En las secciones anteriores se presentó el estado de la educación intercultural y la formación de los docentes en esta materia, con foco en el desarrollo de competencias docentes interculturales para atender la diversidad en el aula; así también, se presentaron las limitantes curriculares en los programas de estudio en la formación inicial y continua de los profesores que impactan en la enseñanza de los estudiantes de las comunidades indígenas. Antes de seguir profundizando en el tema de la formación docente es preciso definir lo que es la educación intercultural como referente teórico para la formación docente:

La educación intercultural es un enfoque educativo basado en el respeto y valoración de la diversidad, dirigido a todos y cada uno de los miembros de la sociedad en su conjunto, que propone un modelo de intervención, formal e informal, holístico, integrado, configurador de todas las dimensiones del proceso educativo en orden a lograr la igualdad de oportunidades/resultados, la superación del racismo en sus diversas manifestaciones, la comunicación y competencia interculturales (Aguado, Ballesteros, Malik y Sánchez, 2003, p. 327).

Efectivamente, el enfoque educativo intercultural centra sus acciones y proyectos educativos en el fortalecimiento de los lazos de integración de las diversas culturas existentes en el territorio oaxaqueño, haciendo referencia al Modelo Educativo Integral Indígena y al documento orientador sobre el trabajo pedagógico de los BIC. Este modelo educativo

Las señalizaciones históricas reseñadas mediante "hitos" son apenas indicativas. Para un panorama completo, amplio y profundo de las cuestiones de desarrollo histórico sobre educación intercultural en diversas formas y autores, véase Bertely et al. (2008). 
considera la cultura local como parte esencial de la formación de los estudiantes ya que los saberes culturales son trasmitidos desde la educación formal e informal. Asimismo, se tiene como objetivo que los integrantes de los grupos culturales del estado interactúen mediante sus manifestaciones culturales sin perder la esencia de su grupo de origen. Sin embargo, la educación intercultural del BIC presenta desafíos que atender, puesto que, a pesar de existir un marco legal constitucional y convenios internacionales que abogan por los derechos de las comunidades a favor de una educación que responda a sus intereses, las políticas educativas interculturales del Estado presentan limitantes para asegurar una educación de calidad. Es por ello, que desde la educación y el rol del docente, se debe atender los siguientes aspectos.

Ante todo, es necesario cultivar actitudes interculturales, es decir, los docentes deben favorecer el desarrollo de competencias comportamentales en sus estudiantes a través de la formación de valores, tanto dentro como fuera del aula, hacia sus compañeros y personas adultas. Así también, deben potenciar el trabajo con la comunidad ya que en ella se conservan aun muchos rasgos valóricos que no deben perderse.

En segundo lugar, se requiere potenciar la convivencia y la cooperación en la medida que el docente intercultural tiene que predicar con el ejemplo dentro del aula y en su contexto, participar de la convivencia de las actividades comunitarias en la que está inserta la escuela y cooperar en la organización de los distintos eventos que no deben ser considerados como ajenos, sino como propios y así encauzar formas de aprendizaje de estas experiencias, desarrollando competencias tanto para estudiantes como para docentes.

En tercer lugar, se debe favorecer la oportunidad de igualdad académicas; esto es, el profesor tiene el compromiso pedagógico de atender la diversidad, no solo desde el punto de vista cultural, sino también en términos de los estilos y ritmos de aprendizaje de los estudiantes, ya que no se debe perder de vista que los jóvenes pueden presentar problemas de aprendizaje por barreras lingüísticas, comprensión, codificación y decodificación de la información, entre otras. Atender estas situaciones favorece un mejor ambiente y clima de aprendizajes, lo que se traduce en igualdad de oportunidades académicas de calidad.

En este sentido, y, en cuarto lugar, la mejora de las competencias de los estudiantes debiera redundar en potenciar el autoconcepto personal. Es un reto importante del profesor para con sus estudiantes de comunidades originarias, ya que por cuestiones ideológicas internas y externas, en la mayoría de los casos son quienes consideran que no tienen oportunidades de aspirar a mejores condiciones sociales y profesionales, por razones de pobreza, marginación, rezago social y económico, discriminación y xenofobia, a pesar de existir programas de inclusión social. El docente intercultural tiene que poseer la competencia de asesorar a sus estudiantes para que se vean como personas valiosas y con las mismas condiciones que los demás, así como proporcionar las herramientas para afrontar las situaciones de la vida.

Finalmente, se debe ser realista y equilibrado, en el sentido de que al diseñar y planificar sus clases, el profesor debe integrar elementos de las ciencias y saberes comunitarios que se relacionen directamente con el tema central, para dar pie a la transversalidad. En la educación intercultural hay que ser realista con lo que se enseña para equilibrar los conocimientos de las ciencias formales y fácticas con los saberes ancestrales de las comunidades, explicando las importancias de esta integración y su aplicación más adelante para que comprendan la importancia de preservar sus conocimientos de generaciones pasadas y las integren con el nuevo saber. 
La formación continua de los docentes de los BIC debe considerar en los currículum y programas de desarrollo profesional, estos aspectos de la educación intercultural como una vía para fortalecer el desarrollo de competencias docentes interculturales. De igual manera, al relacionar dichos aspectos con la formación de los profesores desde un enfoque intercultural, se está potenciando la educación comunitaria como un elemento esencial de este estilo educacional. Por ende, hay que señalar que la "educación comunitaria" en palabras de Maldonado-Alvarado (2016),

es un conjunto no articulado de experiencias pedagógicas de las comunidades locales, retomando los conocimientos propios de la cultura, la ciencia, la filosofía, la religión y otras áreas del conocimiento ancestral de la comunidad y que forman parte de los saberes comunitarios, aportando un baluarte en las ciencias formales y en la educación intercultural de la niñez y juventud oaxaqueña (p. 48).

La educación comunitaria no viene a soslayar el papel de la educación intercultural en la misión y visión de los BIC, al contrario viene a fortalecerla. Este concepto comunitario de educación es utilizado dentro del Modelo Educativo Integral Indígena como eje articulador del trabajo pedagógico de los BIC, el que retoma los saberes en todas las esferas del saber ancestral para enriquecer las prácticas pedagógicas de estudiantes y docentes.

Por lo tanto, los docentes que laboran en los bachilleratos están convocados a fortalecer sus competencias docentes a través de la formación continua para incluir e implementar desde las unidades temáticas y las actividades de enseñanza y aprendizaje los principios de la educación comunitaria propuestos por Maldonado-Alvarado (2016), que bien pueden aportar a las competencias docentes interculturales pensadas para el caso de Oaxaca.

1. La articulación de conocimientos en torno a los saberes locales y regionales: hace referencia a que el docente debe ser capaz de articular los conocimientos de las ciencias formales y factuales con los saberes locales y regionales, propios de las comunidades indígenas, aplicando el enfoque intercultural. Este es un desafío didáctico fundamental y constituye una parte esencial de la tarea implicada en el enfoque intercultural.

2. La investigación como eje pedagógico: en el marco de las nuevas estrategias de enseñanza del Enfoque Basado en Competencias y reforzando a la educación intercultural, se alude a que el profesor potencie el aprendizaje basado en proyectos como parte de las actividades prácticas para desarrollar competencias en los estudiantes, que se traduzcan en más y mejores oportunidades de aprendizaje de calidad.

3. La filosofía comunal como horizonte: es decir, en el proceso de enseñanza y aprendizaje, el profesor tiene que referir, además de ser punto central de la educación intercultural, a los principios filosóficos de la comunidad: cosmovisión, cosmogonía, organización, entre otros.

4. La participación comunitaria en el proceso de aprendizaje: vale decir la comunidad, institución y docentes son los responsables de la formación de los estudiantes, por lo que cada uno asume funciones y responsabilidades propias desde el enfoque intercultural para aportar conocimientos y desarrollar competencias para el aprendizaje de los estudiantes. 
5. El uso extensivo de la lengua originaria: puesto que, si no existe articulación de los saberes globales con los saberes locales, no hay educación intercultural. Es decir, el profesor tiene que desarrollar su trabajo y la interacción educativa, usando la lengua originaria en su forma oral y escrita en las actividades que desarrolla tanto dentro como fuera del aula.

6. Un currículum adecuado a la realidad que se trabaja: que es lo que se viene gestionando desde los comienzos de la educación intercultural. Un currículum que responda a las necesidades de las comunidades originarias, en el que se declaren competencias, módulos de aprendizaje y toda una estructura organizativa del aprendizaje en términos de atención a la diversidad. Sin embargo, es un tema pendiente de las políticas educativas, lo que provoca que el docente aborde temas y contenidos no desde el currículum prescrito sino sobre la base de su experiencia.

7. La colaboración de maestros que más que enseñar, ayudan a aprender: lo que refuerza el principio de la facilitación y mediación del aprendizaje que realiza el docente para generar aprendizajes en sus estudiantes. Así pues, exige desarrollar competencias específicas en su trabajo docente en materias de inclusión y diversidad, de tal forma que sean facilitadores del aprendizaje en la construcción de saberes.

\section{COMPETENCIAS INTERCULTURALES, PERFIL DOCENTE Y MODELO EDUCATIVO INTEGRAL}

Los siete principios de la educación comunitaria aportan elementos sustanciales al desarrollo de competencias interculturales en los docentes, ya que les exige la movilización de recursos internos y externos en el desarrollo de las actividades de enseñanza prescritas en el currículum nacional, de tal forma de garantizar el aprendizaje de los estudiantes y armonizarlos con las líneas de trabajo curricular del Modelo Educativo Integral Indígena de los BIC. Si bien es cierto que la educación intercultural que brindan los bachilleratos se apega a los principios de la interculturalidad, al revisar y analizar el Modelo Educativo Integral Indígena, se determinó que el perfil docente y ámbitos de competencias declaradas necesitan ser perfeccionadas para dar sentido identitario al profesor, acorde con la misión y filosofía educativa institucional.

El documento señala tres aspectos que definen como perfil docente, entre los que se destacan elementos de la actuación del docente (CSEIIO, 2016):

1. Disposición, identificación y compromiso con el pensamiento y trabajo comunitarios: el docente muestra competencias de adaptación psicosocial al medio, disposición de trabajo en las condiciones sociales presentes y una identificación con las necesidades de los estudiantes y la comunidad.

2. Vocación para el servicio docente en contextos interculturales, preferentemente hablante de la lengua indígena de la comunidad y/o región: la responsabilidad, compromiso y ética profesional son los baluartes del profesor intercultural, así como trabajar por brindar una mejor educación y mejores oportunidades para los estudiantes indígenas en su contexto y fuera de ella.

3. Disponibilidad de tiempo para desarrollar trabajos académicos, culturales y 
sociales en y para las comunidades: el profesor debe mostrar competencias para planear, ejecutar y evaluar proyectos en las diferentes áreas y disciplinas que se trabajan en los bachilleratos, lo que exige disposición no solo profesional sino también en tiempos para la implementación de los proyectos.

Por otra parte, al revisar otras fuentes bibliográficas para enriquecer y fortalecer la idea del perfil docente intercultural de los BIC y formular las competencias docentes interculturales, Ipiña (1997) señala la necesidad de integrar elementos de actitud y aptitud en las competencias que debe desarrollar el docente. Estas se dividen en actitudes habituales y aptitudes esenciales.

a) Actitudes habituales:

i. Compromiso con las causas de su pueblo: el profesor intercultural debe mostrar un verdadero compromiso con el desarrollo de su pueblo, no solo en lo educacional sino en las otras áreas, por ejemplo, en la defensa de la dignidad y los derechos de los ciudadanos, así como demostrar compromiso con la formación de los jóvenes de su comunidad.

ii. La tolerancia activa y estimación de lo diferente: el docente intercultural tiene que demostrar apertura, tolerancia y estimación positiva de las diferencias culturales.

iii. La apertura al mundo: ser docente intercultural no significa dejar de interesarse por el progreso y las innovaciones de la ciencia y la tecnología; al contrario, se debe ser una persona abierta a los cambios tecnológicos que incorporará en su trabajo docente. La apertura al mundo es sobrevivir a los tiempos actuales sin renunciar a su cultura.

b) Aptitudes esenciales:

i. Competencia profesional con capacitación constante: es competencia de la función docente la capacitación permanente en aspectos de la gestión del aprendizaje en un enfoque intercultural. Esta capacitación también debe abarcar el desarrollo de proyectos educativos adecuados, planificación y gestión de servicios educativos, entre otros.

ii. La capacidad de investigación y mejoramiento a partir de la experiencia reflexionada: un docente interculturalmente competente debe ser capaz de promover, desarrollar y aplicar la investigación en el contexto educativo.

iii. El dominio de la lengua materna de sus educandos y de la segunda lengua: el profesor intercultural debe dominar la lengua materna de la comunidad y región donde se desempeña, así como también manejar sus metodologías de enseñanza y aprendizaje.

Estos elementos aportan componentes necesarios a considerar para fortalecer el perfil docente de los BIC, a saber: flexibilidad de adaptación a los cambios de la sociedad, capacitación constante en temáticas interculturales, formación de comunidades de aprendizaje e investigación docente. De igual forma, y con el propósito de enriquecer 
la propuesta de trabajo de las competencias docentes interculturales, se revisó el perfil docente y competencias del Bachillerato Intercultural, perteneciente a la Coordinación General de Educación Intercultural y Bilingüe (CGEBI) de la SEP. En tal sentido, el Bachillerato Intercultural ${ }^{5}$ perteneciente a la CGEIB, al igual que el Bachillerato Integral Comunitario, en sus modelos educativos determinaron un perfil de docente y competencias propias para sus profesores. El perfil declara ejes de formación docente que contribuyen al fortalecimiento de las siguientes competencias:

1. Pertinencia cultural y lingüística, que dimensiona la perspectiva histórico-social y favorece la enseñanza y el uso de lenguas.

2. Diálogo de saberes, que se concreta mediante estrategias didácticas que refieren a la dimensión epistemológica a partir del conocimiento de las comunidades y las culturas presentes en el contexto.

3. Formación profesional de vinculación con la comunidad.

4. Diseño de materiales interculturales.

5. Evaluación desde la perspectiva intercultural.

Estos ejes temáticos de formación representan una visión global hacia donde encamina el Bachillerato Intercultural la formación de sus docentes, dando paso a una política educativa acorde a las necesidades de su cuerpo docente, así como también define las estrategias de acción para las capacitaciones futuras.

Por su parte, la Reforma Educativa a la Educación Media Superior, que desde el 2008 plantea la creación de un Sistema Nacional de Bachillerato a nivel nacional, a través de un currículum común (Secretaría de Educación Pública, AS 442: septiembre, 2008) posee como principio el respeto a los diferentes subsistemas y modalidades educativas de bachillerato que se imparten en cada estado, por lo cual les solicita la integración en sus currículum de módulos formativos del tronco común ${ }^{6}$ (currículum nacional) y, a su vez, módulos de educación intercultural propios. Además, la reforma propone un perfil y competencias docentes (Secretaría de Educación Pública, AS 447: septiembre, 2008) y les otorga flexibilidad a los subsistemas para definir los perfiles docentes y las competencias, dependiendo de la especificidad de la modalidad educativa ofrecida.

En cuanto a este punto, el Bachillerato Integral Comunitario debe contener el principio de flexibilidad otorgado por la Reforma Educativa para definir el perfil docente y competencias propias, ya que así se agrega valor a su misión educacional con las comunidades originarias en que presta los servicios educativos. También, así dará mayor sentido de pertenencia a los docentes en su labor con los estudiantes, mediante su participación y compromiso con la educación de los pueblos. Por lo tanto, a partir de los supuestos de la interculturalidad y

\footnotetext{
La Coordinación General de Educación Intercultural y Bilingüe de la Secretaría de Educación Pública ha impulsado desde 2005 el Bachillerato Intercultural, como una propuesta innovadora de educación media superior para reconocer la diversidad cultural, además de garantizar el aprendizaje de los contenidos propios del bachillerato general, que incorpora con pertinencia y calidad el conocimiento y la valoración de la cultura propia y el respeto a otras culturas. El Bachillerato Intercultural tiene entre sus objetivos ofrecer una educación con calidad y pertinencia que promueva el acceso y la permanencia de estudiantes indígenas. La oferta es abierta y dirigida a los egresados de secundaria que desean continuar sus estudios en atención a promover la educación intercultural para todos.

${ }_{6}$ Módulos que son comunes entre los diferentes subsistemas bachillerato en todo México y que pertenecen a un mismo currículum.
} 
la misión de un profesor declarado en los tres ámbitos de acción del MEII, se reelabora el perfil docente intercultural del BIC, quedando de la siguiente forma:

El profesor del Bachillerato Integral Comunitario muestra vocación de servicio docente y habilidades lingüísticas propias de la comunidad en contextos interculturales; participando en cursos de capacitación constante para la atención a la diversidad y los avances de la ciencia y tecnología, así como disposición y compromiso con el pensamiento y trabajo comunitarios a través de investigaciones de orden académico, cultural, social en y para las comunidades.

A partir de la elaboración del perfil docente intercultural del BIC, el siguiente paso es la formulación de las competencias docentes interculturales del $\mathrm{BIC}^{7}$. Cabe señalar que las competencias a declarar retomarán algunas ideas de las establecidas por el Acuerdo Secretarial 447 (Secretaría de Educación Pública, septiembre, 2008), documento base del Servicio Profesional Docente, y las adapta a los principios y características del Modelo Educativo Integral Indígena, a saber:

C1. Organiza su formación continua a lo largo de su trayectoria profesional.

C2. Domina y estructura los saberes para facilitar experiencias de aprendizaje significativo.

C3. Planifica los procesos de enseñanza y de aprendizaje, atendiendo al sistema modular y al enfoque por competencias, y los ubica en contextos disciplinares, curriculares y sociales amplios.

C4. Lleva a la práctica procesos de enseñanza y de aprendizaje de manera efectiva, creativa e innovadora en su contexto institucional.

C5. Evalúa los procesos de enseñanza y de aprendizaje con un enfoque formativo.

C6. Construye ambientes para el aprendizaje autónomo y colaborativo.

C7. Contribuye a la generación de un ambiente que facilite el desarrollo sano e integral de los estudiantes.

C8. Participa en los proyectos de mejora continua de su escuela y apoya la gestión institucional y comunitaria.

Las competencias definidas en el acuerdo 447 son transversales a los diferentes subsistemas de enseñanza media en el país. Es por esto por lo que el Bachillerato Integral Comunitario del estado de Oaxaca posee la facultad de determinar sus competencias docentes desde un enfoque intercultural, retomando los elementos característicos de la pedagogía intercultural que desempeñan los docentes en las aulas y contextos comunitarios. Es importante que el perfil del docente, declarado en el modelo educativo institucional, cuente con competencias que integren conocimientos, habilidades y actitudes para lograr un entorno de aprendizaje significativo.

Las competencias docentes en educación intercultural destacan el carácter práctico de los aprendizajes, en la medida que decimos que la persona es "competente" cuando es capaz de resolver problemas propios de su ámbito de actuación, con atención a la diversidad y a contextos interculturales y dinámicos, esto es, las competencias se adquieren y desarrollan en la acción y se perfeccionan gracias a la misma acción en ámbitos de interacción social. Así pues, para obtener un cambio en las instituciones educativas y

En la enumeración siguiente las competencias se presentas enumeradas desde C1 a C8. 
mejores resultados académicos de los estudiantes se requiere de docentes que se actualicen constantemente y adquieran nuevas competencias para su labor pedagógica, ya que es necesario que los docentes presenten el perfil que las comunidades originarias demandan, dadas sus particularidades específicas y sus rasgos idiosincráticos.

Para avanzar en la dirección necesaria requerida para determinar las competencias que el docente intercultural necesita, deben examinarse, por cierto, autores cuya autoridad en el ámbito de las competencias esté fuera de dudas; pero, al mismo tiempo, se debe establecer un puente entre las competencias, en particular, con los ámbitos de la docencia y la interculturalidad. Se trata, en consecuencia, de una definición que integre docencia, competencias e interculturalidad en una amalgama suficientemente consistente como para servir de base para un programa de acción educativa; para un programa, digamos, de política educativa focalizada en el contexto del Estado de Oaxaca. En fin, este preámbulo sirve para introducirse al estudio de los trabajos de Tejada (2009), las aportaciones de Perrenoud (2004), de la propia Educación Media Superior en México (2008), las contribuciones de Zabalza (2003), Valcárcel (2005), Pérez (2005) y, finalmente, las de Ayala (2008).

El estudio hace suyo el concepto de competencias de Perrenoud (2004) que define la competencia como "una capacidad de movilizar varios recursos internos y externos para hacer frente a un tipo de situaciones" (p. 16). Perrenoud, en su libro Diez nuevas competencias para enseñar (2004) describe minuciosamente diez grandes familias de competencias deseables para la profesión docente, tanto para la formación inicial como para la continua, estas son: organizar y animar situaciones de aprendizaje; gestionar la progresión de los aprendizajes; elaborar y hacer evolucionar dispositivos de diferenciación; implicar al alumnado en su aprendizaje y en su trabajo; trabajar en equipo; participar en la gestión de la escuela; informar e implicar a los padres y madres; utilizar las nuevas tecnologías; afrontar los deberes y dilemas éticos de la profesión y a su vez organizar la formación continua.

Estas diez competencias, engloban muy bien las habilidades, conocimientos y actitudes a adquirir y fortalecer en la labor docente. Igualmente, la familia de competencias no de forma explícita, pero sí implícitamente, aborda elementos de la interculturalidad que los docentes aplican, solo que en este caso hay que ajustarlos a las necesidades de la modalidad educativa de los BIC. Aguaded, de la Rubia y González (2013) definen la competencia intercultural como:

El conjunto de conocimientos, actitudes, aptitudes, habilidades y valores interculturales, junto con unos comportamientos sociales, afectivos, psicológicos, adecuados para relacionarse de manera oportuna en cualquier momento, situación y contexto con cualquier persona sea de la cultura que sea, siendo cada uno/a capaz de autoevaluarse y de aprender de los demás (p. 342).

Estas competencias interculturales interpelan a los docentes que realizan su trabajo profesional en contextos diversos y con demandas curriculares como articular la enseñanza con la ideología de la comunidad, participar en el desarrollo de proyectos comunitarios y trabajar a la par con la familia, entre otros.

Por su parte, Aguaded et al. (2013) definen al profesor competente interculturalmente como aquel que diseña y aplica situaciones de aprendizaje, cuyo objetivo es atender y educar para la diversidad, siendo durante este proceso consciente de sus propias creencias, 
valores, prejuicios y concepciones e intentando comprender la forma de ver el mundo, las actitudes y opiniones de las personas en las que recae su intervención. Un profesor competente, desde la interculturalidad, está en condiciones de gestionar un aprendizaje de calidad e integrador de los saberes globales y locales como una forma de armonizar la enseñanza y la formación de los estudiantes con capacidades y conocimientos sólidos, desarrollando la competencia de transferencia de lo cognitivo a situaciones complejas y diversas. En síntesis, las competencias docentes interculturales tienen efectos en los profesores en el desarrollo del proceso de enseñanza y aprendizaje; puede ser un reto, pero a la vez es una oportunidad de demostrar el dominio de competencias y conocimientos propios (Aneas, 2005).

En primer lugar, se requiere adaptación social, puesto que un docente aspira a un mejor contexto laboral y oportunidades de crecimiento profesional en un ambiente digno. El profesor de educación intercultural, desde su vocación y formación, debe mostrar la convicción de trabajar en un contexto con alto grado de marginación y donde la tarea de mejorar es notoria. Ante este panorama, el docente tiene que adaptarse al contexto y situación, no frustrarse ni mostrar apatía ante la realidad, sino mostrar actitud para ser agente de cambio desde la educación. En segunda instancia, debe mostrar integración cultural, la que le permite al docente integrarse a las actividades y formas organizativas de la comunidad para ir conviviendo, interactuando y aprendiendo de la cultura en la que está inmerso.

Asimismo, el profesor debe incrementar su idoneidad personal, en la medida en que cuenta con la suficiente competencia de adaptación e integración a la comunidad en la que prestará los servicios de educación intercultural, tanto a nivel de conocimientos como de experiencia, para ejercer la profesión con pertinencia y sentido ético.

En función de lo mismo debe evidenciar salud psicológica. En la mayoría de los casos se pudiese pensar que todo docente da por hecho la aceptación de su labor en comunidades originarias. No obstante, esta situación puede generar sentimientos de frustración, apatía, indiferencia y menosprecio por el contexto comunitario cuando no se está preparado psicológicamente para afrontarlo. Finalmente, el docente debe mostrar organización y cooperación, puesto que hoy se enfrenta una renovación en la que los enfoques formativos están orientados al desarrollo de competencias de trabajo colaborativo: a través del intercambio y trabajo mutuo se interactúa con experiencias pedagógicas, didácticas y de conocimientos de las ciencias que pueden ser de interés.

Ahora bien, los efectos de las competencias interculturales tienen un papel destacado en el desarrollo de competencias en la formación inicial y continua de profesores. Por tanto, al haberse reelaborado el perfil docente del Bachillerato Integral Comunitario, a partir de los ámbitos declarados en el MEII (CSEIIO, 2016); siguiendo las competencias del perfil docente del Acuerdo Secretarial 447 (Secretaría de Educación Pública, septiembre, 2008); analizando el perfil y competencias del modelo de Bachillerato Intercultural (CGEIB, 2014); asumiendo la definición de competencia de Perrenoud (2004); además, de la conceptualización de competencia intercultural de Aguado et al. (2008); así como los efectos de las competencias interculturales de Aneas (2005); tanto como el concepto de profesor competente intercultural de Aguaded et al. (2013), se procedió a la formulación de las competencias interculturales para el profesorado del BIC.

La formulación de competencias docentes interculturales responderán a las dimensiones de la interculturalidad propuestas por Paige (2003 citado en Surian, 2012), 
a saber: cualidades personales, habilidades comportamentales, habilidades técnicas, contexto, condiciones socioeconómicas y expectativas de roles. Asimismo, la estructura contemplará los componentes base de la competencia: [verbo + constructo + contexto], que a su vez integra lo conceptual, procedimental y actitudinal, vale decir, los enfoques de competencias de Le Boterf (1994), De Ketele (1996) y Perrenoud (2004). Por ende, las competencias docentes interculturales del Bachillerato Integral Comunitario responderán a una dimensión, a atributos y a indicadores de evaluación.

\subsection{PERFIL DEL PROFESOR DE BACHILLERATO INTEGRAL COMUNITARIO}

Conforme a lo que ha sido dicho previamente, en términos del perfil docente que ha sido indicado, básicamente el profesor o docente con competencias interculturales es un profesional con vocación, con habilidades lingüísticas, en constante capacitación, disponible para el trabajo comunitario y que desarrolla investigación de orden académico, cultural y social en y para las comunidades (García y Oliveras, 1999). La propuesta que sigue es el resultado, en cierto sentido, de una metodología de trabajo desarrollada por García y Oliveras (1999), quienes, mediante un caso, y atendiendo a las particularidades de un cierto contexto educativo, logran dar cuenta de un perfil basado en una determinación de necesidades como se ha hecho común en el campo del diseño curricular por competencias.

El diagnóstico desde el que parten las autoras señaladas es semejante al que guía este estudio, y se asienta en la convicción de que un plan de formación para docentes en competencias interculturales más allá de las generalidades que son propias del enfoque, que debe estar adecuadamente situado, contextualizado y, en virtud de ello, puede acudir de hecho y de derecho al enfoque por competencias (Alarcón, Hill y Frites, 2014). Este conjunto de competencias que integran el perfil del docente intercultural se desglosa en una serie de componentes que se describen a continuación.

Tabla 1. Desglose de competencias de perfil docente intercultural

\begin{tabular}{|c|l|}
\hline Misión de BIC & $\begin{array}{l}\text { Ofrecer educación de calidad al servicio del desarrollo integral de los } \\
\text { pueblos indígenas, a través del Modelo Educativo Integral Indígena de los } \\
\text { Bachilleratos Integrales Comunitarios, promoviendo en los jóvenes la } \\
\text { formación para estudios superiores, el trabajo y el servicio comunitario, } \\
\text { capaces de utilizar los conocimientos, habilidades, actitudes y aptitudes, } \\
\text { para atender a las necesidades del contexto según lo establecido en las } \\
\text { políticas educativas para el nivel medio superior. }\end{array}$ \\
\hline $\begin{array}{c}\text { Filosofía } \\
\text { educativa }\end{array}$ & $\begin{array}{l}\text { Constituirse como un programa de formación educativa con reconocimiento } \\
\text { académico de calidad en la formación de estudiantes de nivel medio superior, } \\
\text { para fortalecer y fomentar sus tradiciones y costumbres: formas de vida, } \\
\text { organización y autonomía de los pueblos indígenas, logrando conocimiento } \\
\text { universal mediante el uso de las herramientas tecnológicas de nuestra época. }\end{array}$ \\
\hline
\end{tabular}




\begin{tabular}{|c|c|c|}
\hline Ámbito & Atributo o competencias & Indicador de desarrollo \\
\hline \multirow[t]{2}{*}{$\begin{array}{l}\text { Gestión del } \\
\text { aprendizaje en } \\
\text { contextos } \\
\text { interculturales }\end{array}$} & $\begin{array}{l}\text { Identificar los elementos de la planifi- } \\
\text { cación disciplinar situándolos en un } \\
\text { contexto intercultural }\end{array}$ & $\begin{array}{l}\text { 1. Planifica las estrategias pedagógi- } \\
\text { cas de la disciplina con un enfo- } \\
\text { que intercultural y por competen- } \\
\text { cias } \\
\text { 2. Aplica estrategias de aprendizaje } \\
\text { en la transferencia de los saberes } \\
\text { de la diversidad cultural en su di- } \\
\text { mensión enriquecedora } \\
\text { 3. Elabora el plan de intervención } \\
\text { psicopedagógica para atender la } \\
\text { diversidad en el aula }\end{array}$ \\
\hline & $\begin{array}{l}\text { Aplicar los principios de la educación } \\
\text { basada en competencias en las relacio- } \\
\text { nes interculturales constructivistas del } \\
\text { proceso de enseñanza y aprendizaje }\end{array}$ & $\begin{array}{l}\text { 1. Selecciona los elementos para la } \\
\text { planificación de la clase según el } \\
\text { modelo por competencias articu- } \\
\text { lándolos con la educación inter- } \\
\text { cultural } \\
\text { 2. } \begin{array}{l}\text { Elabora la secuencia didáctica del } \\
\text { proceso de enseñanza y aprendi- } \\
\text { zaje con estrategias y acciones }\end{array} \\
\text { interculturales } \\
\text { 3. Elabora instrumentos de evalua- } \\
\text { ción auténtica para el contexto } \\
\text { intercultural } \\
\text { 4. Genera ambientes de aprendizaje } \\
\text { interculturales } \\
\text { 5. Diseña materiales didácticos co- } \\
\text { herentes con los contextos inter- } \\
\text { culturales }\end{array}$ \\
\hline \multirow[t]{2}{*}{$\begin{array}{c}\text { Trabajo } \\
\text { colegiado }\end{array}$} & $\begin{array}{l}\text { Organizar intercambios de experien- } \\
\text { cias en comunidades profesionales de } \\
\text { aprendizaje intercultural }\end{array}$ & $\begin{array}{l}\text { 1. Establece periodos de trabajo co- } \\
\text { legiado para el intercambio peda- } \\
\text { gógico } \\
\text { 2. } \begin{array}{l}\text { Promueve comunidades de apren- } \\
\text { dizaje interculturales }\end{array}\end{array}$ \\
\hline & $\begin{array}{l}\text { Planificar las estrategias del plan de } \\
\text { intervención educativa institucional en } \\
\text { atención a la diversidad }\end{array}$ & $\begin{array}{l}\text { 1. Declara las acciones de interven- } \\
\text { ción en base al diagnóstico del } \\
\text { contexto intercultural de la escue- } \\
\text { la } \\
\text { 2. Aplica las estrategias de interven- } \\
\text { ción en los periodos establecidos } \\
\text { en el plan de acción }\end{array}$ \\
\hline
\end{tabular}




\begin{tabular}{|c|c|c|}
\hline \multirow[t]{2}{*}{ Investigación } & $\begin{array}{l}\text { Promover la colaboración recíproca } \\
\text { con expertos en interculturalidad }\end{array}$ & $\begin{array}{l}\text { Participa en eventos de educación in- } \\
\text { tercultural como elemento de mejora } \\
\text { de la práctica docente }\end{array}$ \\
\hline & $\begin{array}{l}\text { Planificar proyectos de investigación } \\
\text { interculturales en el ámbito educativo, } \\
\text { social y cultural }\end{array}$ & 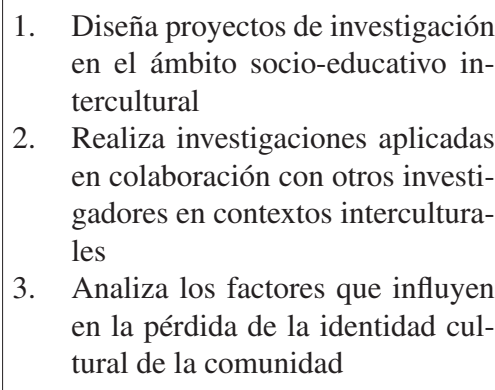 \\
\hline \multirow[t]{2}{*}{$\begin{array}{l}\text { Relación } \\
\text { escuela- } \\
\text { comunidad }\end{array}$} & $\begin{array}{l}\text { Elaborar proyectos interculturales es- } \\
\text { colares y comunitarios para el desarro- } \\
\text { llo local }\end{array}$ & $\begin{array}{l}\text { 1. Organiza eventos de las diversas } \\
\text { manifestaciones culturales dentro } \\
\text { y fuera del aula } \\
\text { 2. Ejecuta acciones de intercambio } \\
\text { de saberes con los habitantes de la } \\
\text { comunidad }\end{array}$ \\
\hline & $\begin{array}{l}\text { Valorar la complejidad del hecho inter- } \\
\text { cultural como elemento enriquecedor } \\
\text { en la sociedad que se inserta la labor } \\
\text { docente }\end{array}$ & $\begin{array}{l}\text { 1. Se relaciona con los padres de fa- } \\
\text { milia en la interacción docente- } \\
\text { tutor } \\
\text { 2. Relaciona la convivencia cultural } \\
\text { como experiencia de aprendizaje } \\
\text { en su formación intercultural }\end{array}$ \\
\hline
\end{tabular}

Fuente. Elaboración propia a partir de la revisión bibliográfica.

En síntesis, el perfil docente del Bachillerato Integral Comunitario cuenta con cuatro ámbitos de acción y nueve competencias, a su vez estas últimas se presentan con sus respectivos indicadores de logro. Con las competencias enunciadas anteriormente, se da identidad profesional a la labor de los docentes interculturales en el Modelo Educativo Integral Indígena. Adicionalmente, como complemento de las competencias, se proponen posibles temas para la formación de docentes interculturales con la finalidad de reforzar, profundizar o ampliar las competencias declaradas.

Estos temas conciernen a la necesidad de elaborar un proyecto educativo intercultural que posibilite adaptaciones curriculares; en segundo lugar, desarrollar estrategias para el cambio sobre la base de la aplicación de actitudes de índole intercultural entre estudiantes y docentes; fomentar la mejora en el rendimiento académico de los estudiantes mediante estrategias para alcanzar éxito escolar; resolver conflictos utilizando estrategias de acción que faciliten la interacción en contextos de diversidad cultural; finalmente, diseñar materiales curriculares con instrumentos de facilitación de aprendizaje y de evaluación. La formulación del perfil docente intercultural y los temas para la formación continua del profesorado se constituirán en las bases que sustenten el trabajo del profesor que se concretarán en los contextos de aula. 
Se puede decir que las competencias docentes interculturales son piezas claves para la labor pedagógica de los profesores que se enfrentan al desafío de la diversidad, cualquiera sea la forma en que esta se manifiesta. Así pues, es tarea de las autoridades educativas generar las condiciones más apropiadas para que tales competencias sean desarrolladas sin que representen una excesiva carga de trabajo para los docentes. Esto, sin embargo, es evidentemente un enorme desafío para la inteligencia de la gestión de sistemas escolares. Por ende, es tarea de directivos y de la administración educativa buscar los mecanismos para armonizar el trabajo, garantizando el desarrollo de las competencias docentes y una educación de calidad para los estudiantes.

\section{CONSIDERACIONES FINALES}

El desarrollo de competencias docentes interculturales en tiempos de reforma educativa es imprescindible ante los cambios estructurales en la educación media superior, lo que, como ha sido dicho, demandó un rediseño curricular y nuevo programas de estudio en la modalidad de educación intercultural del tipo del Bachillerato Integral Comunitario del estado de Oaxaca, lo que sugiere la necesidad de una determinación de competencias docentes propias del Modelo Educativo Integral Indígena.

En efecto, las competencias docentes interculturales formuladas representan pautas que orientan las prácticas pedagógicas de los profesores de este subsistema educativo ante las transformaciones curriculares que exige un docente competente y que esté en condiciones de movilizar una serie de conocimientos y recursos para aplicarlos en el contexto de la interculturalidad; sin embargo, aún queda mucho por hacer en los programas de formación docente en cuanto a la adquisición y aplicación de competencias interculturales en su labor pedagógica.

Entre varios otros autores que han adelantado un punto de vista sobre la interculturalidad en Chile, está Palma (2011), quien se plantea la cuestión del fomento de las competencias interculturales en educación desde la perspectiva del miedo al otro. Siguiendo a Lechner, en efecto, recurre a una clasificación de nuestros miedos, entre los cuales se encuentra en primer lugar el miedo al otro. La nuestra, dice, es una sociedad cuya tesitura interna se revela en el temor al otro y esta constituye la trama que teje el lazo social; y, por cierto, en un contexto tal, ni multilingüe ni multicultural, la interculturalidad no parece ser un artículo de primera necesidad (Loyola y Urbina, 2019). Entonces, por qué promoverla. Este es el aspecto inicial del artículo. Quizás, convenga decir que el asunto ocurre en educación, seguramente porque el espacio educativo es el lugar de la renovación por antonomasia. Aunque, no cabe olvidarlo, es también el lugar de la reproducción cultural y, por lo mismo, forma un enclave social crucial que invita al cambio y lo rehúye. En la educación chilena de los últimos años, si hemos de creer a las cifras, desde al menos 2015, la interculturalidad como modelo educativo se ha situado en primera línea en virtud de la migración (Ministerio de Educación de Chile MINEDUC, 2018; Quilaqueo y Quintriqueo, 2017).

Surgido desde el campo educativo y con aportación desde otros ámbitos como la sociología, la antropología o la sicología, la interculturalidad es un concepto que trata de superar las carencias del concepto de multiculturalismo que, tal vez, denota una situación más bien estática de la sociedad, al contrario que esta, que trata de reflejar, de manera dinámica, la interacción de diferentes culturas entre sí. La interculturalidad, digamos, 
reconoce el conflicto derivado de la confrontación entre contrarios para generar una superación, una sinergia que permita la unidad en la diversidad; pero se trata de una unidad móvil, no estática, no cerrada de una vez y para siempre.

La interculturalidad desde la educación se fundamenta en la consideración de la diversidad humana como oportunidad de intercambio y enriquecimiento frente a la incoherencia pedagógica de la educación monocultural. La noción de interculturalidad introduce una perspectiva dinámica de la cultura y de las culturas; se centra en el contacto y la interacción, en la mutua influencia, el sincretismo, el mestizaje cultural; esto es, la interacción sociocultural en el contexto de la globalización económica, política e ideológica de la revolución tecnológica de las comunicaciones y los transportes. Se habla de ciudadanía común y diferenciada, puesto que, en efecto, hay algo de neobrarroco en todo esto; puesto que la interculturalidad anuda en una síntesis nueva los viejos hábitos, las atávicas costumbres (Sáez, 2008). Lo hace, pero no sin riesgos, por supuesto.

Philippe Perrenoud (2001) sugiere cómo relacionar el proceso de detección de necesidades con la educación basada en competencias, considerando a su vez cómo identificar los campos de desempeño y sus respectivas competencias claves. El punto de vista de Perrenoud a este respecto elabora tanto una propuesta de competencias como un análisis de los campos sociales clave. La articulación de esta perspectiva con el proceso de diagnosticar necesidades debiera ilustrar cómo transitar desde el proceso conceptual al práctico y de este al conceptual y nuevamente al práctico, describiendo así una trayectoria recursiva que corre paralela con la estructura metodológica que también es propia del desarrollo de competencias.

En otras palabras, el enfoque de Perrenoud no consiste en ofrecer alguna clase de orientación para la determinación de necesidades, sino que constituye una verdadera "traducción" de necesidades a competencias, las que a su vez debieran estar normativamente vinculadas a un concepto de desarrollo. Perrenoud señala que el propósito de su trabajo es definir competencias fundamentales para el siglo XXI. Esto indica que la concepción de los objetivos educacionales no corresponde a las necesidades que las personas individual o colectivamente tienen: se requiere un esquema de diseño de formación que, siendo más sensible a los requerimientos de los individuos y las sociedades, satisfaga también requisitos técnico-pedagógicos. Perrenoud señala, además, que la manera de concebir las competencias necesarias no hace más que confirmar una cierta visión del mundo y en la actualidad esta visión está determinada por lo que es políticamente correcto, vale decir, por los patrones de comportamiento que aceptamos como parte de la "vida social normal" (Perrenoud, 2001, p. 5), la que favorece la forma y el estilo de vida de las sociedades privilegiadas.

\section{REFERENCIAS BIBLIOGRÁFICAS}

Aguaded, E., de La Rubia, P. y González, E. (2013). La importancia de la formación del profesorado en competencias interculturales. Revista de currículum y formación del profesorado, 17(1), 339365 .

Aguado, T., Ballesteros, B., Malik, B. y Sánchez, M. (2003). Educación Intercultural en la Enseñanza Obligatoria: Prácticas escolares; actitudes y opiniones de padres, alumnos y profesores. Resultados académicos de los estudiantes de diversos grupos culturales. Revista de Investigación 
Educativa, 21(2), 323-348.

Aguado, T., Gil, I. y Mata, P. (2008). El enfoque intercultural en la formación del profesorado. Dilemas y propuestas. Revista complutense de educación, 19(2), 275-292.

Alarcón, J., Hill, B. y Frites, C. (2014). Educación basada en competencias: hacia una pedagogía sin dicotomías. Educação \& Sociedade, 35(127), 569-586. ISSN 0101-7330. DOI: http://dx.doi. org/10.1590/S0101-73302014000200013. Consulta: 20 de enero, 2019.

Aneas, M. (2005). Competencia intercultural, concepto, efectos e implicaciones en el ejercicio de la ciudadanía. Revista Iberoamericana de Educación, 36(13), 1-9.

Bertely, M., Gasché, J., y Podestá R. (Coords.) (2008). Educando en la diversidad. Investigaciones y experiencias interculturales y bilingües. México: Paidós. Disponible en: http://jgasche.weebly. com/uploads/4/5/0/0/4500630/educando_en_la_diversidad-abya_yala-2008.pdf. Consultado el 20 de febrero, 2019.

CSEIIO. (2016). Plan de estudios. Modelo educativo integral indígena. Ciudad de Oaxaca: CSEIIO.

CGEIB. (2014). Bachillerato intercultural. Modelo Educativo, características y operación. Ciudad de México: SEP.

De Ketele, J. M. (1996). L'évaluation des acquis scolaires: quoi? pourquoi? pour quoi? Revue tunisienne des sciences de l'éducation, 23(17-36).

Dietz, G. (2014). Educación intercultural en México. Revista de Investigación Educativa, (18), 172-181.

Ettayebi, M., Opertti, R. y Jonnaert, Ph. (2008). Logique de compétences et dévelopement curriculaire. Débats, perspectives et alternative pour les systèmes éducatifs. París: Harmattan.

García, M. y Oliveras, E. (1999). Formación del profesorado en educación intercultural: Un caso práctico. Revista interuniversitaria. Formación del profesorado, (36), 199-209.

Gómez, M. (2010). Competencias interculturales en instructores comunitarios que brindan servicios a la población indígena del Estado de Chiapas. Revista Electrónica de Investigación Educativa, 12(1), 1-25. Disponible en http://redie.uabc.mx/vol12no1/contenido-gomezzermeno.html. Consulta: 13 de septiembre, 2019.

Ipiña, E. (1997). Condiciones y perfil del docente en educación intercultural bilingüe. Revista Iberoamericana de Educación, (13), 99-109.

Jiménez, C. y Malgesini, G. (1997). Guía de conceptos sobre migraciones, racismo e interculturalidad. Madrid: Ed. La cueva del oso.

Le Boterf, G. (1994). De la compétence: essai sur un attacteur étrange. París: Les Editions d'Organisation.

Loyola, I. y Urbina, M. (2019). Los tres hitos sobre migración en 2018: quiénes hablaron y qué dijeron en las redes sociales. Santiago de Chile: CIPER Chile.

Maldonado-Alvarado, B. (2016). Hacia un país plural: educación comunitaria en Oaxaca frente a la política interculturalidad cero. Revita LiminaR. Estudios Sociales y Humanísticos, XIV(1), 47-59.

Ministerio de Educación de Chile. (MINEDUC) (2018). Política nacional de estudiantes extranjeros 2018-2022. Disponible en: https://migrantes.mineduc.cl/wp-content/uploads/sites/88/2018/06/ POLITICA-NACIONAL-EE-Final-1-1.pdf. Consulta: 22 de febrero, 2019.

Organización Internacional del Trabajo. (1989). Convenio $N^{o} 169$ Sobre Pueblos Indígenas y Tribales en Países Independientes. Disponible en: https://www.mop.cl/asuntosindigenas/Documents/ convenio169.pdf. Consulta: 13 de marzo, 2019.

Palma, I. (2011). ¿Cómo fomentar competencias interculturales, en la educación formal, en un país racista que teme a la otredad? Synergies Chili, (7), 137-155.

Perrenoud, Ph. (1998). La qualité d'une formation se joued'abord dans sa conception dans sa conception. Pédagogie collégiale, 11(4), 16-22.

. (2001). La clave de los campos sociales: competencia del actor autónomo. En D. Simone y L. Hersh, Definir y seleccionar las competencias fundamentales para la vida (pp. 216-250). México: Fondo de Cultura Económica. 
. (2004). Diez nuevas competencias para enseñar. Barcelona: Graó.

Presidencia de la República. (2014). Programa especial de educación intercultural 2014-2018. Ciudad México: Diario Oficial de la Federación.

Quilaqueo, D. y Quintriqueo, S. (2017). Métodos educativos mapuches: Retos de la doble racionalidad educativa. Temuco: Universidad Católica de Temuco.

República de los estados unidos mexicanos. (2019). Constitución política de los estados mexicanos. Disponible en: https://www.juridicas.unam.mx/legislacion/ordenamiento/constitucion-politicade-los-estados-unidos-mexicanos\#10536 Consulta: 13 de marzo, 2019.

Sáez, R., (2008). La educación intercultural. Revista de Educación, X(339), 859-881.

Secretaría de Educación Pública. (septiembre, 2008). Acuerdo secretarial 447. Competencias docentes de Educación Media Superior. Disponible en: www.sep.gob.mx Consulta: 3 de febrero de 2019.

Surian, A. (2012). Aprendizaje y competencias interculturales. Ra Ximhai, 8(2), 205-222.

Tardif, J. (2003). Développer un programme par compétences: de l'intention á la mise en oeuvre. Pédagogie Collégiale, 16(3), 36-44.

Tejada, J. (2009). Competencias docentes. Profesorado. Revista de currículum y formación del profesorado, 13(2), 1-16.

UNESCO. (2002). Declaración Universal sobre la Diversidad Cultural. Series sobre la diversidad cultural $n^{\circ} 1$. Johannesburgo.

Valverde, A. (2010). La formación docente para una educación intercultural en la educación secundaria. Revista Cuicuilco, 17(48), 133-147. 
